\title{
OPEN The incidence of myocardial infarction and stroke in head and neck cancer patients
}

\author{
Hyun-Keun Kwon ${ }^{1}$, Kyung-Do Han ${ }^{2}$, Yong-Il Cheon ${ }^{1}$, Sung-Chan Shin ${ }^{1}$, Minhyung Lee ${ }^{3}$, \\ Eui-Suk Sung ${ }^{3}$, Jin-Choon Lee ${ }^{3} \&$ Byung-Joo Lee ${ }^{1 \bowtie}$
}

Various treatment modalities are used for head and neck cancer (HNC). This study analyzed the incidence and risks of myocardial infarction (MI) and stroke by cancer site and treatment modality in 22,737 patients newly diagnosed with HNC registered in the Korean National Health Insurance Service database in 2007-2013. An additional 68,211 patients without HNC, stroke, or MI were identified as the control group. The risks for MI (hazard ratio [HR]=1.38, 95\% confidence interval [CI] 1.24-1.53), stroke $(\mathrm{HR}=1.48,95 \% \mathrm{Cl} 1.37-1.60)$, and mortality $(\mathrm{HR}=5.30,95 \% \mathrm{Cl} 5.14-5.47)$ were significantly higher in the HNC group. Analysis by cancer site showed the risk of MI and mortality was highest in hypopharynx cancer, while the risk of stroke was highest in nasopharynx and paranasal sinus cancer. Analysis by treatment modality showed the highest risks for $\mathrm{MI}(\mathrm{HR}=1.88,95 \% \mathrm{Cl} 1.31-2.69)$ and mortality ( $\mathrm{HR}=2.95,95 \% \mathrm{Cl} 2.75-3.17)$ in $\mathrm{HNC}$ patients receiving chemotherapy $(\mathrm{CT})$ alone, while HNC patients receiving $\mathrm{CT}$ with surgery had the highest risk for stroke $(\mathrm{HR}=1.81,95 \% \mathrm{Cl} 1.14-2.88)$. Careful attention to $\mathrm{MI}$ and stroke risks in HNC patients is suggested, especially those who received both CT and radiotherapy.

Head and neck cancer (HNC) is a group of cancers occurring in the tongue and oral cavity, oropharynx, nasopharynx and paranasal sinus, hypopharynx, larynx, salivary gland, and others. HNC is the ninth most common malignancy worldwide, and recent US cancer statistics indicated that more than 65,000 men and women were diagnosed with HNC in $2017^{1,2}$. Tobacco and alcohol are the most important risk factors for the development of HNC, especially due to their synergic effects ${ }^{3}$. Despite advances in various therapeutic options in the treatment of HNC, its mortality rate is high due to the high rates of local recurrence and regional metastasis ${ }^{4}$. Since most of these patients are diagnosed at advanced stages, they undergo multimodal therapy, thereby leading to significant acute and chronic side effects ${ }^{5}$.

Stroke is a common complication in cancer patients, with tumor-related disorders, coagulation disorders, infection, cancer treatment complications, and paraneoplastic causes reported as associated factors ${ }^{6-11}$. Radiation therapy (RT) for HNC has been shown to damage cerebrovasculature ${ }^{12}$; RT increases the risk of stroke by $40-46 \%$ in HNC patients ${ }^{12,13}$. In addition to RT, chemotherapy (CT), which is widely used in the treatment of HNC patients, causes coagulation disturbances and direct endovascular damage, leading to vascular complications ${ }^{14-16}$. Several studies have reported that CT increases the risk of stroke ${ }^{17,18}$. Both RT and CT increase the risk of thromboembolic events, which can increase the risk of myocardial infarction (MI) as well as stroke.

While many studies have reported an increased risk of stroke after treatment for HNC, none have shown an increased risk of MI. Thus, we investigated the incidence and risk of MI and stroke in HNC patients compared to those of the general population. We hypothesized that the risk of MI and stroke in HNC patients would vary between cancer site and treatment modality.

\section{Results}

Characteristics of the study population. The HNC and control groups had similar age and sex distributions. Of the 22,737 HNC patients, 17,166 (75.5\%) were male and 5571 (24.5\%) were female. The mean age in both groups was $58.65 \pm 13.22$ years, with most patients aged $60-79$ years $(10,633$ of $22,737,46.77 \%)$. The preva-

\footnotetext{
${ }^{1}$ Department of Otorhinolaryngology-Head and Neck Surgery, College of Medicine, Pusan National University and Medical Research Institute, Pusan National University Hospital, 179 Gudeok-ro, Seo-gu, Busan 49241, South Korea. ${ }^{2}$ Department of Statistics and Actuarial Science, Soongsil University, Seoul, South Korea. ${ }^{3}$ Department of Otorhinolaryngology-Head and Neck Surgery, College of Research Institute for Convergence of Biomedical Science and Technology, Pusan National University Yangsan Hospital, Yangsan, South Korea. ${ }^{\circledR}$ email: voiceleebj@ gmail.com
} 


\begin{tabular}{|l|l|l|l|}
\hline & Control (N=68,211) & HNC (N=22,737) & \multirow{2}{*}{ P value } \\
\cline { 2 - 3 } & $\mathbf{N}(\%)$ & $\mathbf{N}(\%)$ & 1 \\
\hline Age (years) & & & \\
\hline $0-19$ & $597(0.88)$ & $199(0.88)$ & \\
\hline $20-39$ & $4848(7.11)$ & $1616(7.11)$ & \\
\hline $40-59$ & $28,533(41.83)$ & $9511(41.83)$ & \\
\hline $60-79$ & $31,899(46.77)$ & $10,633(46.77)$ & \\
\hline$\geq 80$ & $2334(3.42)$ & $778(3.42)$ & \\
\hline Mean \pm SD & $58.65 \pm 13.22$ & $58.65 \pm 13.22$ & \\
\hline Sex (male) & & & 1 \\
\hline Male & $51,498(75.5)$ & $17,166(75.5)$ & \\
\hline Female & $16,713(24.5)$ & $5571(24.5)$ & \\
\hline Comorbidity & & & \\
\hline HTN & $20,892(30.63)$ & $7534(33.14)$ & $<0.0001^{*}$ \\
\hline DM & $8224(12.06)$ & $3359(14.77)$ & $<0.0001^{*}$ \\
\hline Dyslipidemia & $9280(13.6)$ & $2994(13.17)$ & 0.095 \\
\hline Income level & & & $<0.0001^{*}$ \\
\hline Q1 (lowest) & $18,962(27.8)$ & $6515(28.65)$ & \\
\hline Q2 & $14,599(21.4)$ & $4982(21.91)$ & \\
\hline Q3 & $15,826(23.2)$ & $5330(23.44)$ & \\
\hline Q4 (highest) & $18,824(27.6)$ & $5910(25.99)$ & \\
\hline
\end{tabular}

Table 1. Baseline characteristics of the study population. $H N C$ head and neck cancer, $S D$ standard deviation, HTN hypertension, $D M$ diabetes mellitus. ${ }^{\star} P<0.05$.

\begin{tabular}{|c|c|c|c|c|}
\hline & $\mathbf{N}$ & Events & IR (per 1000) & Adjusted HR (95\% CI) \\
\hline \multicolumn{5}{|l|}{ MI } \\
\hline Control & 68,211 & 1422 & 3.388 & 1 (Ref.) \\
\hline $\mathrm{HNC}$ & 22,737 & 467 & 4.424 & $1.376(1.239,1.528)^{\star}$ \\
\hline \multicolumn{5}{|l|}{ Stroke } \\
\hline Control & 68,211 & 2567 & 6.165 & 1 (Ref.) \\
\hline $\mathrm{HNC}$ & 22,737 & 887 & 8.480 & $1.483(1.374,1.602)^{\star}$ \\
\hline \multicolumn{5}{|c|}{ Mortality } \\
\hline Control & 68,211 & 7281 & 17.204 & 1 (Ref.) \\
\hline HNC & 22,737 & 9206 & \begin{tabular}{|l|}
86.548 \\
\end{tabular} & $5.3(5.138,5.466)^{*}$ \\
\hline
\end{tabular}

Table 2. Comparisons of MI, stroke, and mortality risks between the HNC and control groups. IR incidence rate, $H R$ hazard ratio adjusted for age, sex, hypertension, diabetes mellitus, dyslipidemia, CI confidence interval, $H N C$ head and neck cancer, $M I$ myocardial infarction. ${ }^{\star} P<0.05$.

lence of hypertension and DM was higher in the HNC group than that in the control group (33.14\% vs. $30.63 \%$ and $14.77 \%$ vs. $12.06 \%$ respectively; all $P<0.001)$ s(Table 1$)$.

MI, stroke, and mortality risks in the HNC group compared to those in the control group. After 5-10 years of follow-up, we identified 467 cases of MI, 887 cases of stroke, and 9206 cases of mortality in the HNC group and 1422 cases of MI, 2567 cases of stoke, and 7281 cases of mortality in the control group. Compared to the control group, the overall incidence rates of MI (4.42 vs. 3.39), stroke (8.48 vs. 6.16), and mortality (86.55 vs. 17.20) were higher in the HNC group. The risks for MI (hazard ratio [HR] $=1.38,95 \%$ confidence interval $[\mathrm{CI}] 1.24-1.53)$, stroke $(\mathrm{HR}=1.48,95 \% \mathrm{CI} 1.37-1.60)$, and mortality $(\mathrm{HR}=5.30,95 \%$ CI $5.14-5.47)$ were also higher in the HNC group (Table 2). The incidence probabilities of MI and stroke and the survival probabilities in the HNC and control groups are shown in Fig. 1. In the HNC group, the incidence of MI, stroke, and mortality appeared to occur immediately within 2 years, and as the follow-up period was prolonged, an increase in imbalance between groups was observed $(P<0.0001)$.

MI, stroke, and mortality risks in the HNC group by cancer site. We investigated the risks of MI, stroke, and mortality at each HNC site. Compared to the control group, patients with hypopharynx cancer had higher risks of $\mathrm{MI}(\mathrm{HR}=2.40,95 \% \mathrm{CI} 1.85-3.11)$ and mortality ( $\mathrm{HR}=9.01,95 \% \mathrm{CI} 8.48-9.58)$, whereas those with nasopharynx and paranasal sinus cancer had a higher risk of stroke (HR=2.22, 95\% CI 1.91-2.58) (Table 3). The incidence probabilities of MI and stroke and survival probabilities by cancer site in the HNC 
A

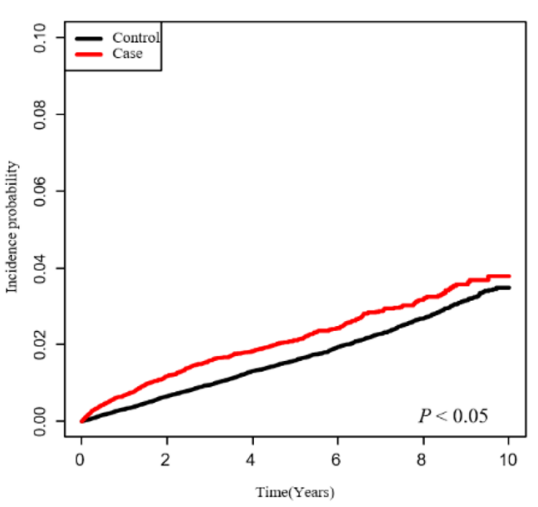

B

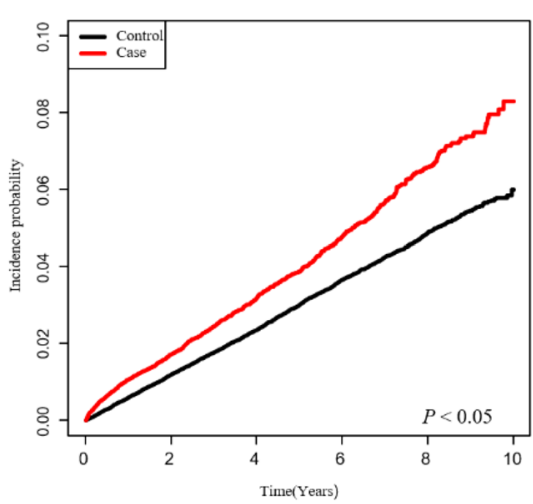

C Mortality

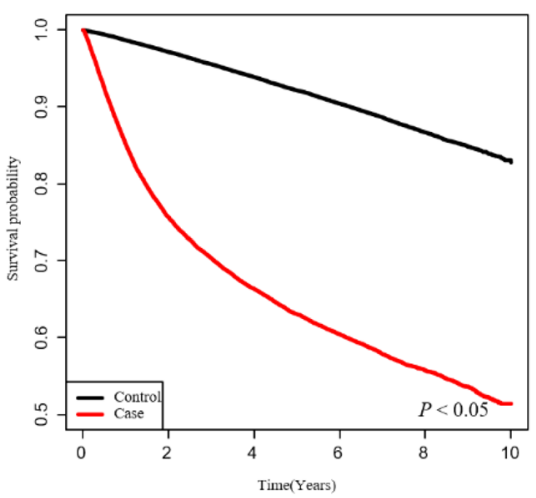

Figure 1. Kaplan-Meier analysis comparing incidence and survival probability between HNC patients and reference cohort. $M I$ myocardial infarction.

\begin{tabular}{|c|c|c|c|c|}
\hline Type & $\mathbf{N}$ & Events & IR (per 1000) & Adjusted HR (95\% CI) \\
\hline \multicolumn{5}{|l|}{ MI } \\
\hline Control & 68,211 & 1422 & 3.388 & 1 (Ref.) \\
\hline Tongue and oral cavity & 4319 & 78 & 4.123 & $1.401(1.114,1.762)^{\star}$ \\
\hline Oropharynx & 3143 & 58 & 4.031 & $1.381(1.061,1.797)^{*}$ \\
\hline Nasopharynx and paranasal sinus & 4545 & 77 & 3.572 & $1.505(1.195,1.895)^{*}$ \\
\hline Hypopharynx & 1801 & 59 & 10.184 & $2.396(1.845,3.112)^{*}$ \\
\hline Larynx & 6462 & 174 & 5.351 & $1.282(1.095,1.502)^{*}$ \\
\hline Salivary gland and others & 2467 & 21 & 1.697 & $0.696(0.452,1.072)$ \\
\hline \multicolumn{5}{|l|}{ Stroke } \\
\hline Control & 68,211 & 2567 & 6.165 & 1 (Ref.) \\
\hline Tongue and oral cavity & 4319 & 107 & 5.664 & $1.106(0.911,1.343)$ \\
\hline Oropharynx & 3143 & 125 & 8.793 & $1.75(1.461,2.095)^{*}$ \\
\hline Nasopharynx and paranasal sinus & 4545 & 188 & 8.830 & $2.219(1.911,2.577)^{\star}$ \\
\hline Hypopharynx & 1801 & 93 & 16.234 & $2.098(1.705,2.582)^{*}$ \\
\hline Larynx & 6462 & 299 & 9.285 & $1.205(1.068,1.359)^{*}$ \\
\hline Salivary gland and others & 2467 & 75 & 6.111 & $1.454(1.155,1.832)^{\star}$ \\
\hline \multicolumn{5}{|l|}{ Mortality } \\
\hline Control & 68,211 & 7281 & 17.204 & 1 (Ref.) \\
\hline Tongue and oral cavity & 4319 & 1849 & 96.950 & $6.691(6.354,7.046)^{\star}$ \\
\hline Oropharynx & 3143 & 1160 & 80.011 & $5.389(5.064,5.736)^{*}$ \\
\hline Nasopharynx and paranasal sinus & 4545 & 1895 & 87.421 & $7.395(7.025,7.784)^{*}$ \\
\hline Hypopharynx & 1801 & 1208 & 205.639 & $9.014(8.477,9.584)^{\star}$ \\
\hline Larynx & 6462 & 2309 & 70.304 & $3.312(3.16,3.472)^{*}$ \\
\hline Salivary gland and others & 2467 & 785 & 63.280 & $5.26(4.883,5.666)^{\star}$ \\
\hline
\end{tabular}

Table 3. Comparisons of MI, stroke, and mortality risks between the HNC and control groups. IR incidence rate, $H R$ hazard ratio adjusted for age, sex, hypertension, diabetes mellitus, dyslipidemia, $C I$ confidence interval, $M I$ myocardial infarction. ${ }^{\star} P<0.05$.

and control groups are shown in Fig. 2. In the HNC group excluding the salivary gland and others group, the incidence probability of MI was similar or higher than that of the control group $(P<0.0001)$. In the HNC group excluding the tongue and oral cavity, salivary gland and others group, the incidence probability of stroke was higher than that of the control group $(P<0.0001)$. All HNC subgroups had a lower survival probability compared to the control group $(P<0.0001)$.

MI, stroke, and mortality risks in the HNC group by age and sex. The risks of MI, stroke, and mortality were analyzed according to age and sex within the HNC group. When analyzed by age, the risks for MI $(\mathrm{HR}=8.34,95 \% \mathrm{CI} 4.18-16.63)$, stroke $(\mathrm{HR}=10.99,95 \% \mathrm{CI} 6.04-19.97)$, and mortality $(\mathrm{HR}=8.43,95 \% \mathrm{CI}$ 7.38-9.63) were highest in people over 80 years of age. When analyzed by sex, the incidence rates and risks of MI, stroke, and mortality were higher in male patients (Table 4). 
A

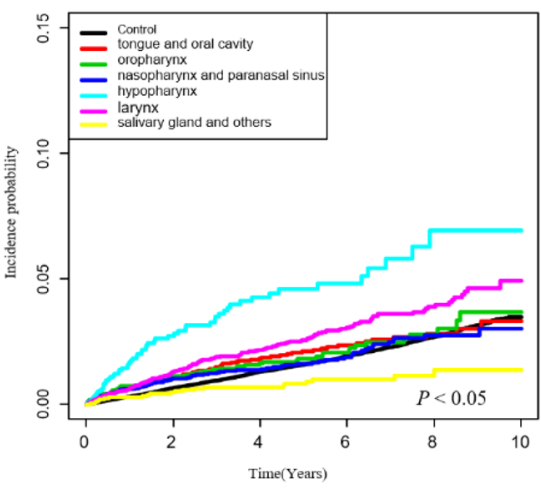

$\mathrm{B}$

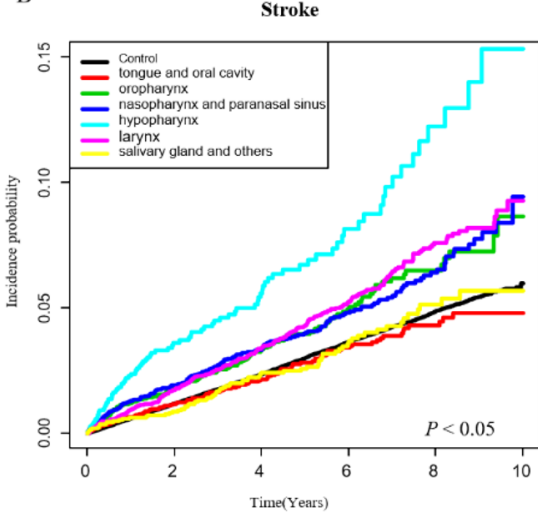

$\mathrm{C}$

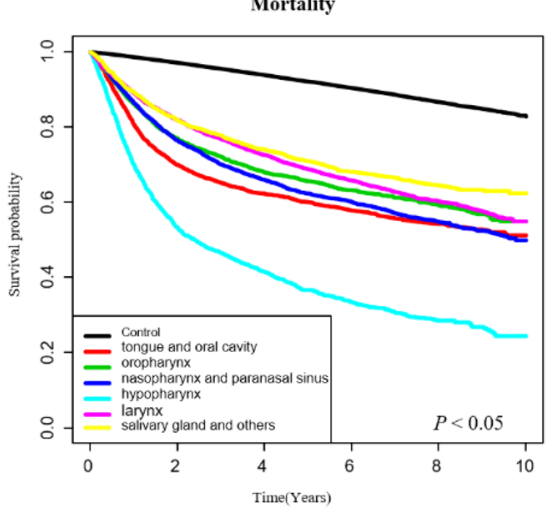

Figure 2. Kaplan-Meier analysis comparing incidence and survival probability by cancer site. MI myocardial infarction.

\begin{tabular}{|c|c|c|c|c|}
\hline Type & $\mathbf{N}$ & Events & IR (per 1000) & Adjusted HR (95\% CI) \\
\hline \multicolumn{5}{|l|}{ MI } \\
\hline \multicolumn{5}{|l|}{ Age } \\
\hline $0-19$ & 199 & 1 & 0.836 & $0.631(0.082,4.851)$ \\
\hline $20-39$ & 1616 & 12 & 1.345 & 1 (Ref.) \\
\hline $40-59$ & 9511 & 121 & 2.485 & $1.543(0.85,2.801)$ \\
\hline $60-79$ & 10,633 & 305 & 6.814 & $3.872(2.155,6.958)^{*}$ \\
\hline$\geq 80$ & 778 & 28 & 14.106 & $8.341(4.183,16.632)^{*}$ \\
\hline \multicolumn{5}{|l|}{ Sex } \\
\hline Male & 17,166 & 388 & 4.987 & 1 (Ref.) \\
\hline Female & 5571 & 79 & 2.847 & $0.646(0.506,0.824)^{*}$ \\
\hline \multicolumn{5}{|l|}{ Stroke } \\
\hline \multicolumn{5}{|l|}{ Age } \\
\hline $0-19$ & 199 & 2 & 1.660 & $0.965(0.221,4.222)$ \\
\hline $20-39$ & 1616 & 15 & 1.683 & 1 (Ref.) \\
\hline $40-59$ & 9511 & 244 & 5.041 & $2.671(1.583,4.506)^{*}$ \\
\hline $60-79$ & 10,633 & 584 & 13.232 & $6.558(3.908,11.005)^{*}$ \\
\hline$\geq 80$ & 778 & 42 & 21.631 & $10.987(6.044,19.973)^{*}$ \\
\hline \multicolumn{5}{|l|}{ Sex } \\
\hline Male & 17,166 & 749 & 9.728 & 1 (Ref.) \\
\hline Female & 5571 & 138 & 4.998 & $0.568(0.473,0.682)^{*}$ \\
\hline \multicolumn{5}{|c|}{ Mortality } \\
\hline \multicolumn{5}{|l|}{ Age } \\
\hline $0-19$ & 199 & 33 & 27.380 & $0.657(0.46,0.938)^{\star}$ \\
\hline $20-39$ & 1616 & 363 & 40.587 & 1 (Ref.) \\
\hline $40-59$ & 9511 & 2864 & 58.532 & $1.396(1.251,1.558)^{*}$ \\
\hline $60-79$ & 10,633 & 5330 & 117.720 & $2.964(2.66,3.302)^{\star}$ \\
\hline$\geq 80$ & 778 & 616 & 306.089 & $8.43(7.379,9.632)^{\star}$ \\
\hline \multicolumn{5}{|l|}{ Sex } \\
\hline Male & 17,166 & 7339 & 93.527 & 1 (Ref.) \\
\hline Female & 5571 & 1867 & 66.919 & $0.879(0.835,0.925)^{*}$ \\
\hline
\end{tabular}

Table 4. MI, stroke, and mortality risks in the HNC group by age and sex. $I R$ incidence rate, $H R$ hazard ratio adjusted for age, sex, hypertension, diabetes mellitus, dyslipidemia, $C I$ confidence interval, $M I$ myocardial infarction. ${ }^{*} P<0.05$.

MI, stroke, and mortality risks in the HNC group by treatment modality. The risks of MI, stroke, and mortality were analyzed according to treatment modality in the HNC group. Compared to patients with no treatment, the risk of $\mathrm{MI}$ was highest in patients receiving $\mathrm{CT}$ alone ( $\mathrm{HR}=1.88,95 \% \mathrm{CI} 1.31-2.69)$, the risk of stroke was highest in patients receiving both surgery and CT ( $\mathrm{HR}=1.81,95 \% \mathrm{CI} 1.14-2.88)$, and the risk of mortality was highest in patients receiving CT alone ( $\mathrm{HR}=2.95,95 \% \mathrm{CI} 2.75-3.17)$ (Table 5). 


\begin{tabular}{|c|c|c|c|c|}
\hline & $\mathbf{N}$ & Events & IR (per 1000) & Adjusted HR (95\% CI) \\
\hline \multicolumn{5}{|l|}{ MI } \\
\hline No treatment & 7056 & 151 & 4.15758 & 1 (Ref.) \\
\hline Surgery alone & 2630 & 51 & 3.45079 & $0.845(0.615,1.161)$ \\
\hline CT alone & 1783 & 38 & 5.82242 & $1.876(1.308,2.689)^{\star}$ \\
\hline RT alone & 3567 & 77 & 4.582 & $1.032(0.783,1.359)$ \\
\hline Surgery +CT & 330 & 4 & 2.99694 & $0.854(0.316,2.309)$ \\
\hline Surgery+RT & 1779 & 29 & 3.17693 & $0.836(0.562,1.245)$ \\
\hline $\mathrm{CT}+\mathrm{RT}$ & 4071 & 92 & 6.01654 & $1.576(1.209,2.055)^{\star}$ \\
\hline Surgery+CT+RT & 1521 & 25 & 4.65853 & $1.212(0.79,1.859)$ \\
\hline \multicolumn{5}{|l|}{ Stroke } \\
\hline No treatment & 7056 & 339 & 9.4626 & 1 (Ref.) \\
\hline Surgery alone & 2630 & 97 & 6.6152 & $0.719(0.574,0.902)^{*}$ \\
\hline CT alone & 1783 & 47 & 7.2256 & $1.021(0.751,1.389)$ \\
\hline RT alone & 3567 & 133 & 7.959 & $0.805(0.659,0.985)^{\star}$ \\
\hline Surgery $+\mathrm{CT}$ & 330 & 19 & 14.4549 & $1.81(1.139,2.877)^{*}$ \\
\hline Surgery+RT & 1779 & 61 & 6.7278 & $0.787(0.599,1.034)$ \\
\hline $\mathrm{CT}+\mathrm{RT}$ & 4071 & 140 & 9.2268 & $1.121(0.917,1.371)$ \\
\hline Surgery+CT + RT & 1521 & 51 & 9.5414 & $1.17(0.869,1.576)$ \\
\hline \multicolumn{5}{|l|}{ Mortality } \\
\hline No treatment & 7056 & 2604 & 71.135 & 1 (Ref.) \\
\hline Surgery alone & 2630 & 552 & 37.116 & $0.535(0.488,0.586)^{*}$ \\
\hline CT alone & 1783 & 1144 & 174.063 & $2.954(2.752,3.17)^{*}$ \\
\hline RT alone & 3567 & 1272 & 74.98 & $0.974(0.911,1.042)$ \\
\hline Surgery+CT & 330 & 194 & 145.275 & $2.257(1.95,2.612)^{*}$ \\
\hline Surgery+RT & 1779 & 571 & 62.182 & $0.913(0.833,0.999)$ \\
\hline $\mathrm{CT}+\mathrm{RT}$ & 4071 & 2004 & 129.861 & $1.849(1.742,1.962)^{\star}$ \\
\hline Surgery+CT+RT & 1521 & 865 & 160.094 & $2.282(2.11,2.468)^{*}$ \\
\hline
\end{tabular}

Table 5. MI, stroke, and mortality risk in the HNC group by treatment modality. IR incidence rate, $H R$ hazard ratio adjusted for age, sex, hypertension, diabetes mellitus, dyslipidemia, CI confidence interval, $M I$ myocardial infarction, $R T$ radiation therapy, $C T$ chemotherapy. ${ }^{\star} P<0.05$.

\section{Discussion}

To our knowledge, this is the first nationwide study to investigate the relative risks of MI, stroke, and mortality incidences among HNC patients who underwent surgery, CT, and RT compared to a general non-cancer control population matched for age and sex. After adjusting for age, sex, and comorbidities such as hypertension (HTN), diabetes mellitus (DM), and dyslipidemia, the risks of MI, stroke, and mortality were significantly higher in the HNC group compared to those in the control group. Analysis by cancer site showed the highest risk of MI and mortality in patients with hypopharynx cancer, while the risk of stroke was highest in patients with nasopharynx and paranasal sinus cancer. Analysis by treatment modality showed high incidences of MI, stroke, and mortality for treatment with CT alone or with surgery or RT. After adjusting for age, sex, and comorbidities, the risks of $\mathrm{MI}$ and stroke were highest in patients who received CT alone or with surgery.

HTN, DM, and dyslipidemia are well-known risk factors for vascular events such as stroke and $\mathrm{MI}^{19,20}$. In addition, studies on the effects of HTN, DM, and dyslipidemia on the development of cancer are ongoing. A previous large, population-based case-control study reported inverse associations between type II DM, HTN, dyslipidemia, and $\mathrm{HNC}^{21}$. However, in the present study, the incidence of HTN and DM were higher in HNC patients than in the controls. Even after adjusting for the risk factors of vascular events such as DM, HTN, and dyslipidemia, the risks of stroke and MI remained higher in HNC patients.

Previous studies reported the highest and lowest 5-year HNC survival rates for lip cancer and hypopharyngeal cancer, respectively ${ }^{22,23}$. The 8th edition of the American Joint Committee on Cancer (AJCC) divides lip cancer into mucosal and cutaneous lip. Mucosal lip is included in the oral cavity while cutaneous lip is included in cutaneous carcinoma of the head and neck ${ }^{24}$. Thus, this study included mucosal lip cancer as an oral cavity cancer. When lip cancer was excluded from previous studies, salivary gland cancer had the highest 5-year survival rate in $\mathrm{HNC}^{22,23}$. In the present study, larynx cancer showed the lowest mortality risk and hypopharynx cancer showed the highest mortality risk in HNC patients.

Several HNC cohort studies have investigated the risk of stroke following treatment. A population-based study similar to the present study reported that HNC patients are at increased risk of developing stroke, especially the young age group and those who received both RT and $\mathrm{CT}^{25}$. In our study, HNC increased the risk of stroke by $48.3 \%$ compared to control. However, unlike the previous study, the stroke risk increased with age and the stroke risk was highest in patients in the present study who received both surgery and CT. 
Many studies have shown that RT is associated with increased risks of cerebrovascular disease in HNC patients. The exact mechanism of radiation-induced carotid or cerebral artery injury is not clear but is thought to be due to endothelial dysfunction, injury and occlusion of the vasa vasorum, and accelerated atherosclerosis ${ }^{26,27}$. Several population-based cohort studies reported increased cerebrovascular risk in HNC patients who underwent RT alone compared to that in patients who underwent surgery with or without radiation ${ }^{12,28}$. A recent populationbased cohort study reported that the risk of stroke increased with RT after adjusting for other socioeconomic and clinical risk factors. The authors suggested that attention should be paid to advanced-age patients with low socioeconomic status and known clinical risk factors of stroke ${ }^{13}$. However, in the present study, patients who received RT alone or surgery with or without radiation had lower risks of stroke than those who received no treatment and the stroke risk was highest in patients who underwent both surgery and CT.

The risk of thromboembolic events increases after chemotherapy in patients with various cancers. Ischemic cerebrovascular accidents caused by chemotherapy have been reported in various cancers, including HNC, breast cancer, and lymphoma ${ }^{17,29-31}$. The mechanism of chemotherapy-induced thromboembolism is also not clear, although tumor embolization, vasculitis, nonbacterial thrombotic endocarditis, consumption coagulopathy, or complications related to chemotherapeutic agents have been suggested as causes of thromboembolism ${ }^{18,32,33}$. Cisplatin is the main anti-cancer drug in CT of HNC and commonly causes cerebrovascular events ${ }^{18}$. After CT with cisplatin, cerebrovascular accidents occur due to vasospasm, hyperreninemia or hyperaldosteronemia, platelet hyperaggregation, decreased tissue activators, endothelial dysfunction, and elevated serum cholesterol levels ${ }^{18,34-37}$.

There have also been reports of chemotherapy-induced cardiotoxicity (CIC). CIC occurs due to the direct effect of the drug on the cardiovascular system or indirect effects due to thrombogenic status or hemodynamic flow alterations ${ }^{38}$. The risk of CIC development is affected by several factors, including the type of chemotherapy agent, the administered dose, and the drug administration rate ${ }^{39,40}$. However, to our knowledge, there have been no reports of increased MI after treatment in HNC patients. Although the mechanism is not clear, the results of this study showed an increased incidence of MI after treatment in HNC patients, especially in those who received CT alone.

Contrary to previous studies, where the risk of stroke increases due to RT, the group receiving both surgery and CT in the present study showed the highest stroke incidence rate or HR. According to the results of this study, CT appeared to increase the risks of MI, stroke, and mortality more than RT. Patients who received CT alone are likely to have received palliative CT due to advanced stage or underlying diseases. Therefore, the highest mortality rate among patients who received CT alone may have been affected by complications such as MI and stroke.

This study has several limitations. First, alcohol consumption, smoking, and body mass index (BMI) are important risk factors for stroke and MI as well as HNC. However, the KNHIS data did not provide information on alcohol consumption, smoking and BMI. Second, the type and administered dose of CT agent and the intensity of RT used in treatment could not be confirmed. Finally, our study was based on an Asian population; thus, the results may be different in Western populations. Therefore, our results need to be analyzed in other ethnic groups.

In conclusion, the results of our study showed increased MI and stroke risks among HNC patients compared to those in the general non-cancer population. After adjusting for age, sex, and comorbidities, the risks of MI and mortality were highest in hypopharynx cancer, while the risk of stroke was highest in nasopharynx and paranasal sinus cancer. Analysis by treatment modality showed that the risks of MI, stroke, and mortality were highest in the group that received CT alone or with surgery. Therefore, careful attention to MI and stroke risk for HNC patients is suggested, especially in those who receive both CT and RT.

\section{Methods}

Data source. The Korean National Health Insurance Service (KNHIS) is the public medical insurance system administered by the Ministry for Health, Welfare and Family Affairs ${ }^{41}$. As a compulsory social insurance system, the KNHIS program includes approximately $97 \%$ of the entire Korean population. Individuals in the lowest income level bracket (approximately 3\% of the population) are covered by the Medical Aid program. The KNHIS database includes patient demographics and records on diagnosis (based on International Classification of Diseases, 10th revision, Clinical Modification [ICD-10-CM] codes), interventions, and prescriptions ${ }^{42}$. Additionally, the KNHIS provides a biennial national health check-up program for all beneficiaries aged $\geq 40$ years old or employees regardless of age ${ }^{43}$. This program aims to detect cardiovascular risk factors, including age, sex, smoking status, alcohol consumption, hypertension, DM, and dyslipidemia, for subsequent educational counseling.

The KNHIS database has been widely used in numerous epidemiological and health services-related research studies $^{44}$. Its detailed profile and configuration have been previously described ${ }^{45,46}$. The research protocol was approved by the Institutional Review Board of the Pusan National University Hospital and informed consent was waived.

Study population and design. From KNHIS data, we identified 22,737 cases of HNC (ICD-10-CM code C01-14, C30-33, C43.2, and C44.2), newly diagnosed in 2007-2013. Patients with prior stroke (ICD-10-CM code I63-64) or MI (ICD-10-CM code I21-22) were excluded. HNC included malignant neoplasms of the tongue and oral cavity (19.0\%), oropharynx (13.8\%), nasopharynx and paranasal sinus (20.0\%), hypopharynx (7.9\%), larynx (28.4\%), and salivary gland and others (10.9\%). The follow-up period was calculated from the date of HNC diagnosis. For the selection of the control group, we used a ratio of 1:3; thus, 68,211 individuals free from any cancer and prior stroke or MI and matched for age, sex. Baseline comorbidities were evaluated during the study period. Baseline characteristics of the comorbidities were extracted from the medical claims according 
to the ICD-10-CM codes. We included hypertension, DM, and dyslipidemia. Income level was categorized into quartiles based on individual insurance contribution; the medical aid population ( $3 \%$ of Korean population) were merged with the lowest income quartile group for the analyses. The index dates were randomly selected as the control group.

The design of this study was as follows; (1) analyze the incidence and risks of MI, stroke, and mortality in the total HNC and control groups; (2) analyze the incidence and risk of MI, stroke, and mortality by HNC site (tongue and oral cavity, oropharynx, nasopharynx and paranasal sinus, hypopharynx, larynx, salivary gland, and others); and (3) analyze the incidence and risks of MI, stroke, and mortality by age, sex, and treatment modality (no treatment, surgery alone, RT alone, CT alone, surgery and CT, surgery and RT, concurrent chemoradiation therapy (CCRT), surgery and CCRT) in the HNC group.

Statistical analysis. We compared the distributions of demographic status and comorbidity between the $\mathrm{HNC}$ and control groups using chi-square tests for categorical variables and $t$-test for continuous variables. We calculated the incidence rates of MI, stroke, and mortality by dividing the number of incident cases by the total follow-up period. The incidence rates of MI, stroke, and mortality are presented as 1000 person-years. The hazard ratios (HRs) and 95\% confidence intervals (95\% CIs) describing the risks of stroke, MI and mortality were calculated using Cox regression models adjusted for age, sex, and other comorbidities, including hypertension, DM, dyslipidemia, and income. The incidence and survival probability was calculated by using the KaplanMeier curves, and the log-rank test was performed to analyze differences among the groups.

The HNC group was compared to the control group. To assess the risk of MI, stroke, and mortality by HNC site, the study population was divided into six subgroups based on ICD-10-CM code (tongue and oral cavity, oropharynx, nasopharynx and paranasal sinus, hypopharynx, larynx, salivary gland, and others). To assess the effect of therapy, the study population was divided into seven subgroups based on treatment modality (no treatment, surgery alone, RT alone, CT alone, surgery and CT, surgery and RT, concurrent chemoradiation therapy (CCRT), surgery and CCRT). Statistical analyses were performed using SAS version 9.2 (SAS Institute, Cary, NC, USA). A two-sided $P$-value $<0.05$ was considered to indicate statistical significance.

\section{Data availability}

The datasets generated during and/or analyzed during the current study are available from the corresponding author on reasonable request.

Received: 20 August 2020; Accepted: 12 January 2021

Published online: 18 February 2021

\section{References}

1. Ferlay, J. et al. Cancer incidence and mortality worldwide: Sources, methods and major patterns in GLOBOCAN 2012. Int. J. Cancer 136, E359-E386. https://doi.org/10.1002/ijc.29210 (2015).

2. Siegel, R. L., Miller, K. D. \& Jemal, A. Cancer Statistics, 2017. CA Cancer J. Clin. 67, 7-30. https://doi.org/10.3322/caac.21387 (2017).

3. Alam, M. S., Siddiqui, S. A. \& Perween, R. Epidemiological profile of head and neck cancer patients in Western Uttar Pradesh and analysis of distributions of risk factors in relation to site of tumor. J. Cancer Res. Ther. 13, 430-435. https://doi.org/10.4103/09731482.180687 (2017).

4. Argiris, A., Karamouzis, M. V., Raben, D. \& Ferris, R. L. Head and neck cancer. Lancet 371, 1695-1709. https://doi.org/10.1016/ s0140-6736(08)60728-x (2008).

5. Goyal, M. et al. Cardiovascular sequel of neck irradiation in head and neck cancer patients. Int. J. Radiat. Biol. 93, 711-716. https ://doi.org/10.1080/09553002.2017.1303217 (2017).

6. Cestari, D. M., Weine, D. M., Panageas, K. S., Segal, A. Z. \& DeAngelis, L. M. Stroke in patients with cancer: Incidence and etiology. Neurology 62, 2025-2030. https://doi.org/10.1212/01.wnl.0000129912.56486.2b (2004).

7. Grisold, W., Oberndorfer, S. \& Struhal, W. Stroke and cancer: A review. Acta Neurol. Scand. 119, 1-16. https://doi.org/10.111 $1 / j .1600-0404.2008 .01059 . x(2009)$.

8. Lindvig, K., Moller, H., Mosbech, J. \& Jensen, O. M. The pattern of cancer in a large cohort of stroke patients. Int. J. Epidemiol. 19, 498-504. https://doi.org/10.1093/ije/19.3.498 (1990).

9. Nguyen, T. \& DeAngelis, L. M. Stroke in cancer patients. Curr. Neurol. Neurosci. Rep. 6, 187-192. https://doi.org/10.1007/s1191 0-006-0004-0 (2006).

10. Rogers, L. R. Cerebrovascular complications in cancer patients. Neurol. Clin. 21, 167-192. https://doi.org/10.1016/s0733 -8619(02)00066-x (2003).

11. Zhang, Y. Y., Chan, D. K., Cordato, D., Shen, Q. \& Sheng, A. Z. Stroke risk factor, pattern and outcome in patients with cancer. Acta Neurol. Scand. 114, 378-383. https://doi.org/10.1111/j.1600-0404.2006.00709.x (2006).

12. Arthurs, E., Hanna, T. P., Zaza, K., Peng, Y. \& Hall, S. F. Stroke after radiation therapy for head and neck cancer: What is the risk?. Int. J. Radiat. Oncol. Biol. Phys. 96, 589-596. https://doi.org/10.1016/j.ijrobp.2016.07.007 (2016).

13. Lee, J. Y. et al. Radiotherapy can increase the risk of ischemic cerebrovascular disease in head and neck cancer patients: A Korean population-based cohort study. Radiother. Oncol. 142, 85-91. https://doi.org/10.1016/j.radonc.2019.09.025 (2020).

14. Digklia, A. \& Voutsadakis, I. A. Acute cerebrovascular accident after cisplatin treatment in a patient taking letrozole. Chemotherapy 58, 435-438. https://doi.org/10.1159/000345793 (2012).

15. Nuver, J. et al. Acute chemotherapy-induced cardiovascular changes in patients with testicular cancer. J. Clin. Oncol. 23, 9130-9137. https://doi.org/10.1200/JCO.2005.01.4092 (2005).

16. Sekijima, T. et al. Impact of platinum-based chemotherapy on the progression of atherosclerosis. Climacteric 14, 31-40. https:// doi.org/10.3109/13697137.2010.522278 (2011).

17. Bachaud, J. M. et al. Predictive factors of a complete response to and adverse effects of a CDDP-5FU combination as primary therapy for head and neck squamous carcinomas. J. Laryngol. Otol. 107, 924-930. https://doi.org/10.1017/s0022215100124806 (1993).

18. Li, S. H. et al. Incidence of ischemic stroke post-chemotherapy: A retrospective review of 10,963 patients. Clin. Neurol. Neurosurg. 108, 150-156. https://doi.org/10.1016/j.clineuro.2005.03.008 (2006). 
19. Galassi, A., Reynolds, K. \& He, J. Metabolic syndrome and risk of cardiovascular disease: A meta-analysis. Am. J. Med. 119, 812-819. https://doi.org/10.1016/j.amjmed.2006.02.031 (2006).

20. Guzik, A. \& Bushnell, C. Stroke epidemiology and risk factor management. Continuum (Minneap Minn) 23, 15-39. https://doi. org/10.1212/CON.0000000000000416 (2017).

21. Stott-Miller, M., Chen, C. \& Schwartz, S. M. Type II diabetes and metabolic syndrome in relation to head and neck squamous cell carcinoma risk: A SEER-Medicare database study. Cancer Epidemiol. 37, 428-433. https://doi.org/10.1016/j.canep.2013.03.006 (2013).

22. Guntinas-Lichius, O. et al. Head and neck cancer in Germany: A site-specific analysis of survival of the Thuringian cancer registration database. J. Cancer Res. Clin. Oncol. 136, 55-63. https://doi.org/10.1007/s00432-009-0636-y (2010).

23. Carvalho, A. L., Nishimoto, I. N., Califano, J. A. \& Kowalski, L. P. Trends in incidence and prognosis for head and neck cancer in the United States: A site-specific analysis of the SEER database. Int. J. Cancer 114, 806-816. https://doi.org/10.1002/ijc.20740 (2005).

24. Zanoni, D. K., Patel, S. G. \& Shah, J. P. Changes in the 8th Edition of the American Joint Committee on Cancer (AJCC) Staging of Head and Neck Cancer: Rationale and Implications. Curr. Oncol. Rep. 21, 52. https://doi.org/10.1007/s11912-019-0799-x (2019).

25. Chu, C. N. et al. Increase in stroke risk in patients with head and neck cancer: A retrospective cohort study. Br. J. Cancer 105, 1419-1423. https://doi.org/10.1038/bjc.2011.361 (2011).

26. Xu, J. \& Cao, Y. Radiation-induced carotid artery stenosis: A comprehensive review of the literature. Interv. Neurol. 2, $183-192$. https://doi.org/10.1159/000363068 (2014).

27. Louis, E. L., McLoughlin, M. J. \& Wortzman, G. Chronic damage to medium and large arteries following irradiation. J. Can. Assoc. Radiol. 25, 94-104 (1974).

28. Smith, G. L. et al. Cerebrovascular disease risk in older head and neck cancer patients after radiotherapy. J. Clin. Oncol. 26, 5119-5125. https://doi.org/10.1200/JCO.2008.16.6546 (2008).

29. Cassi, E. et al. A cooperative study on ProMACE-CytaBOM in aggressive non-Hodgkin's lymphomas. Leuk. Lymphoma 13, 111-118. https://doi.org/10.3109/10428199409051660 (1994).

30. Licciardello, J. T., Moake, J. L., Rudy, C. K., Karp, D. D. \& Hong, W. K. Elevated plasma von Willebrand factor levels and arterial occlusive complications associated with cisplatin-based chemotherapy. Oncology 42, 296-300. https://doi.org/10.1159/000226049 (1985).

31. Wall, J. G. et al. Arterial thrombosis associated with adjuvant chemotherapy for breast carcinoma: A Cancer and Leukemia Group B Study. Am. J. Med. 87, 501-504. https://doi.org/10.1016/s0002-9343(89)80604-7 (1989).

32. Weijl, N. I. et al. Thromboembolic events during chemotherapy for germ cell cancer: A cohort study and review of the literature. J Clin Oncol 18, 2169-2178. https://doi.org/10.1200/jco.2000.18.10.2169 (2000).

33. Azak, A., Oksüzoğlu, B., Deren, T., Oneç, B. M. \& Zengin, N. Cerebrovascular accident during cisplatin-based combination chemotherapy of testicular germ cell tumor: An unusual case report. Anticancer Drugs 19, 97-98. https://doi.org/10.1097/CAD.0b013 e3282f0777e (2008).

34. Raghavan, D., Cox, K., Childs, A., Grygiel, J. \& Sullivan, D. Hypercholesterolemia after chemotherapy for testis cancer. J. Clin. Oncol. 10, 1386-1389. https://doi.org/10.1200/JCO.1992.10.9.1386 (1992).

35. Ito, H., Okafuji, T. \& Suzuki, T. Vitamin E prevents endothelial injury associated with cisplatin injection into the superior mesenteric artery of rats. Heart Vessels 10, 178-184. https://doi.org/10.1007/BF01744983 (1995).

36. Ruiz, M. A. et al. The influence of chemotherapy on plasma coagulation and fibrinolytic systems in lung cancer patients. Cancer 63, 643-648. https://doi.org/10.1002/1097-0142(19890215)63:4\%3c643::aid-cncr2820630407\%3e3.0.co;2-j (1989).

37. Bosl, G. J. et al. Increased plasma renin and aldosterone in patients treated with cisplatin-based chemotherapy for metastatic germ-cell tumors. J. Clin. Oncol. 4, 1684-1689. https://doi.org/10.1200/JCO.1986.4.11.1684 (1986).

38. Albini, A. et al. Cardiotoxicity of anticancer drugs: The need for cardio-oncology and cardio-oncological prevention. J. Natl. Cancer Inst. 102, 14-25. https://doi.org/10.1093/jnci/djp440 (2010).

39. Ghatalia, P., Je, Y., Kaymakcalan, M. D., Sonpavde, G. \& Choueiri, T. K. QTc interval prolongation with vascular endothelial growth factor receptor tyrosine kinase inhibitors. Br. J. Cancer 112, 296-305. https://doi.org/10.1038/bjc.2014.564 (2015).

40. Shakir, D. K. \& Rasul, K. I. Chemotherapy induced cardiomyopathy: Pathogenesis, monitoring and management. J. Clin. Med. Res. 1, 8-12. https://doi.org/10.4021/jocmr2009.02.1225 (2009)

41. Kim, D. S. Introduction: Health of the health care system in Korea. Soc. Work Public Health 25, 127-141. https://doi. org/10.1080/19371910903070333 (2010).

42. Yhim, H. Y. et al. Incidence of venous thromboembolism following major surgery in Korea: From the Health Insurance Review and Assessment Service database. J. Thromb. Haemost. 12, 1035-1043. https://doi.org/10.1111/jth.12611 (2014).

43. Lee, H. et al. Association of cardiovascular health screening with mortality, clinical outcomes, and health care cost: A nationwide cohort study. Prev. Med. 70, 19-25. https://doi.org/10.1016/j.ypmed.2014.11.007 (2015).

44. Shin, D. W., Cho, B. \& Guallar, E. Korean National Health Insurance Database. JAMA Intern. Med. 176, 138. https://doi.org/10.1001/ jamainternmed.2015.7110(2016).

45. Cheol Seong, S. et al. Data resource profile: The National Health Information Database of the National Health Insurance Service in South Korea. Int. J. Epidemiol. 46, 799-800. https://doi.org/10.1093/ije/dyw253 (2017).

46. Song, S. O. et al. Background and data configuration process of a nationwide population-based study using the korean national health insurance system. Diabetes Metab. J. 38, 395-403. https://doi.org/10.4093/dmj.2014.38.5.395 (2014).

\section{Acknowledgements}

This work was supported by grants from the Korean Society of Otorhinolaryngology-Head and Neck Surgery and a National Research Foundation of Korea (NRF) grant funded by the Korea government (MSIT) (Nos. NRF2017R1E1A1A01074316 and NRF-2016R1D1A3B01015539).

\section{Author contributions}

Y.I.C. and S.C.S. performed the experiments. H.K.K., K.D.H., M.H.L., and E.S.S. analyzed the data. J.C.L. and B.J.L. designed the study. H.K.K. wrote the manuscript with the contribution of all coauthors. J.C.L. and B.J.L. supervised the study.

\section{Competing interests}

The authors declare no competing interests.

Additional information

Correspondence and requests for materials should be addressed to B.-J.L.

Reprints and permissions information is available at www.nature.com/reprints. 
Publisher's note Springer Nature remains neutral with regard to jurisdictional claims in published maps and institutional affiliations.

(c) (i) Open Access This article is licensed under a Creative Commons Attribution 4.0 International License, which permits use, sharing, adaptation, distribution and reproduction in any medium or format, as long as you give appropriate credit to the original author(s) and the source, provide a link to the Creative Commons licence, and indicate if changes were made. The images or other third party material in this article are included in the article's Creative Commons licence, unless indicated otherwise in a credit line to the material. If material is not included in the article's Creative Commons licence and your intended use is not permitted by statutory regulation or exceeds the permitted use, you will need to obtain permission directly from the copyright holder. To view a copy of this licence, visit http://creativecommons.org/licenses/by/4.0/.

(C) The Author(s) 2021 